\title{
An Overview of Learning Support Factors on Mathematic Games
}

\author{
Ahmad Fairuzabadi ${ }^{* 1}$, Ahmad Afif Supianto ${ }^{2}$ \\ 1,2Universitas Brawijaya, Malang Indonesia \\ zabedhasekar@gmail.com*1, afif.supianto@ub.ac.id ${ }^{2}$
}

\begin{abstract}
In this study, we examined the factors in game design that were used by developers to support the interests of mathematics learning. The aim is to overcome the lack of empirical evidence about the impact of factors in the game on learning outcomes, identify how the design of in-game activities affects learning, and develop an overview of general recommendations for designing mathematics education games. This study tries to illustrate the impact of game design factors in mathematics education games on the objectives and results of game-based learning.
\end{abstract}

Keywords: Game-based Learning, Educational Game, Mathematical Game, Game design, Main-gaming Elements

\section{Introduction}

In recent years there has been an increasing interest in the use of digital games for learning with the increasing number of conferences, journals, projects and communities working on this topic. Most of this interest is speculative, discussing the potential of the game to provide new methods to support learning. One of the best-selling subjects is in mathematics [1]. To address concerns about the lack of empirical evidence about the effectiveness of the game, Connolly, Boyle, Hainey, McArthur, and Boyle (2012) [2] conducted a literature review aimed at identifying research evidence about the positive impact of the game. The research confirms that research on games is very diverse related to the focus of learning, and the intended results. But the research was still researching in all fields of learning. Whereas in mathematics subjects also have a variety of studies related to the focus of learning in mathematics and learning objectives.

This study seeks to identify and illustrate opportunities offered in games for the benefit of mathematics learning. Some of the material that will be discussed is about what type of game is appropriate to support mathematics learning in a particular subject area, and about what factors support learning in order to achieve learning goals.

Before starting this research, a literature review has been conducted on similar studies that discuss educational games, especially about the influence of gameplay on learning. There have been previous researchers who conducted systematic literature reviews that discussed the effects of gameplay on learning outcomes or objectives.

Jabbar and Felicia (2015) [3] in a systematic literature review, they examined the features in educational games that support the learning process. The purpose of their research is to overcome the lack of empirical evidence about the influence of game design used for learning on learning outcomes at the cognitive and emotional level. This research collects articles from several databases, namely: ERIC, Academic Search Complete, PsycINFO, ISI Web of Knowledge, Wiley Online Library, JSTOR, Emerald Journals, Science Direct, ACM dl, and IEEE Xplore. Articles obtained at the initial stage of the search amounted to 3174, which finally after passing screening according to inclusion and duplication criteria, left 91 scientific papers to be reviewed and examined. This study states that the type of game and the main elements in the game are including factors that influence learning outcomes. This study also discusses the influence of the main elements in the game and the type of game on the effects that are caused which affect players on an emotional or cognitive level. In the end, this study concluded that the gameplay did affect the learning outcomes. But this research has not specifically described the relationship between gameplay design like what is capable of supporting each of the different subjects.

In addition, Boyle et al. (2016) [1] also conducted a systematic literature review that discussed the impact of computer games and serious-game. This study aims to identify research

Fairuzabadi, A., \& Supianto, A. (2019). An Overview of Learning Support Factors on Mathematic Games. Kinetik: Game Technology, Information System, Computer Network, Computing, Electronics, and Control, 4(2). doi:http://dx.doi.org/10.22219/kinetik.v4i2.761

Receive February 24, 2019; Revise March 16, 2019; Accepted May 21, 2019 
evidence about the positive impact of the game. Articles collected were obtained from several online data bases, namely: BioMed Central, ASSIA, ERIC, IEEE, Ingenta, and Science Direct. The initial number obtained was 54,580 articles, which finally after going through various screening processes obtained 143 articles that were considered appropriate for research in the study. This study found that educational games are used to train skills and increase knowledge, while entertainment games are able to provide affective effects, behavior changes and physiological results. The study also found that the most popular subject disciplines using games as a learning tool were Science, Technology, Engineering, and Mathematics (STEM) and followed after that was the health field. From this, it can be concluded that indeed Mathematics is the subject area that has found many problems in its learning, but there is still no empirical evidence that provides an explanation of game design that can support its learning. Therefore, this study tries to provide empirical evidence about the factors that influence learning outcomes in Mathematics courses using educational media games.

\section{Research Method}

To obtain empirical evidence about the factors that support mathematics learning using games, we conducted an overview using systematic methods such as the following.

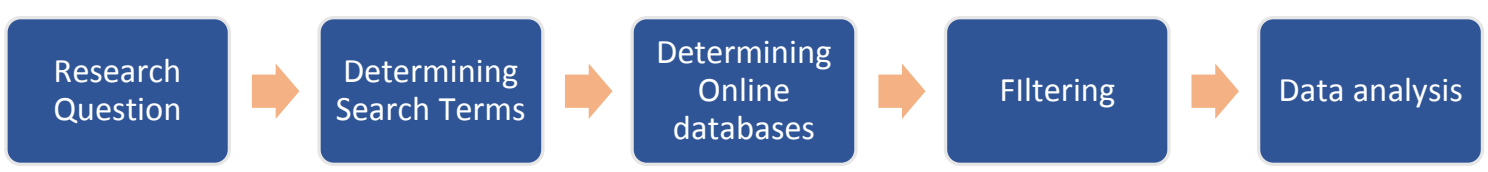

Figure 1. Research Method

Figure 1 illustrates the steps taken in this study to achieve the objectives of this study. This research method consists of:

1. Determining the research questions $(R Q)$. The formulation of the problem consists of important points which are the main points of the problem in this study trying to be solved.

2. Determining search terms. Search terms that are made must be in accordance with the need to find studies that can answer the formulation of the problems that have been made.

3. Determining online data-base. The selected databases are credible scientific sites that publish recognized scientific research journals. The journals published by these sites must be in accordance with the expected domain of research. In the search for online databases restrictions were made on the publishing year for these studies. This is done to reduce the bias of findings that are not relevant for the present.

4. Screening research that has been obtained from the online databases that have been determined, and by using search terms that have been made. This is intended to select studies that can answer research questions.

5. After obtaining articles that are considered relevant for review in this study, an analysis of these studies is carried out by mapping the answers to the research questions contained in these articles. To facilitate this process, it is done using the Spreadsheet. After the required data is obtained, a study is conducted on the relationship between variables with one another, for example is the relationship between the type of game and the learning objectives. So from this stage, new findings are obtained in this study.

\subsection{Research Questions}

From the background and purpose of this research which has been presented in the previous chapter, it can be concluded that all the research sought must be able to answer three questions: (RQ1) What type of game is used?, (RQ2) What are the main elements of the game applied in the game used?, and (RQ3) What evaluation method is used to measure the results of the study?

\subsection{Search Terms}

From the formulation of the problem that has been explained, it is necessary to determine several terms for the purpose of searching for studies which are assumed to be able to answer all the problem formulations. Search terms used include various terms related to educational games: (AND games (educational OR online OR computer OR serious OR simulation)) (A1), as well as the term subject of learning namely Mathematics: AND (math OR mathematics) ( A2) and

KINETIK Vol. 4, No. 2, May 2019: 169-178 
terms for possible outcomes or effects of playing the game: AND (impacts OR effects OR outcomes OR affect) (A3) AND (learning OR skills OR knowledge OR instruction OR strategies) (A4) AND (motivation OR engagement OR behavior OR emotion OR enjoyment) (A5).

\subsection{Online Databases}

In this study, the database used for searching the scientific papers is the international journal sites indexed by Scopus. These sites are as follows: Institute of Electrical and Electronics Engineers (IEEE), ScienceDirect, SpringerLink, Digital Library Association for Computing Machinery (ACM), and Education Resources Information Center (ERIC). In the search, restrictions were also made on the publication of articles. These articles must be published in the last 5 years, namely from 2014 to 2018 . This is done to maximize the search for research that is still relevant for the present.

\subsection{Filters}

To get studies that are considered feasible to answer the problem formulations in this study, it is necessary to filter out these studies by using certain constraints. So to do the screening, two layers of filters were made to identify feasible studies.

\section{B1. Title \& Abstract}

The first filter used is to examine each title and abstract of the studies that have been obtained from searches based on the terms and limits of the last 5 years on a database that has been determined. Each research title and abstract must be related to mathematics learning using educational games or games.

\section{B2. The answers of $R Q$}

The second filter is to understand the contents of the research that has been obtained, whether there are answers to each RQ (Research Question) that has been determined. This is done to be able to eliminate bias and collect clear empirical evidence to meet the objectives of this study.

\section{Results and Discussion}

\subsection{Papers identified by search terms}

Based on the search terms that have been made, a number of papers are assumed to be in accordance with the needs of this research. In the search process on each database, the last 5 years are restricted to the publication of each scientific paper. The articles sought are in the form of research reports in the form of scientific journals and proceedings. The number of scientific papers obtained based on search terms in all predetermined databases is 174 scientific papers. Table 1 provides information about the number of papers obtained in each database.

\section{Table 1. Article Search Results Based on Search Terms}

\begin{tabular}{ccccccc}
\hline Journal & A1 & A2 & A3 & A4 & A5 & Percentage \\
\hline IEEE & 13521 & 692 & 101 & 67 & 17 & $10 \%$ \\
ScienceDirect & 1071 & 51 & 16 & 16 & 16 & $9 \%$ \\
SpringerLink & 745 & 122 & 117 & 117 & 105 & $60 \%$ \\
ACM & 6462 & 432 & 122 & 65 & 30 & $17 \%$ \\
ERIC & 192 & 37 & 22 & 21 & 6 & $4 \%$ \\
\hline Number & 21991 & 1334 & 378 & 286 & 174 & $100 \%$ \\
\hline
\end{tabular}

In Table 1, it can be seen that SpringerLink was ranked first in the number of articles obtained based on search terms with 105 articles (60\%). And ERIC in the last sequence is only 6 scientific papers (4\%).

\subsection{Filtered Papers}

After obtaining a number of articles that are sought based on search terms, it is necessary to do a screening to get studies that are worthy of research in this study. Filtering is done with 2 screening stages. Table 2 contains data on the number of papers obtained after experiencing 2 filter processes. 
The first stage of screening is to read each title and abstract of each scientific writing obtained. A brief overview of the titles and abstracts of scientific papers is related to research that uses games as a means of learning mathematics. After initial screening, 40 scientific papers were deemed appropriate.

Then the second stage of screening is carried out by reading the whole contents of each scientific paper that has been selected from the initial screening stage. At this stage, the choosen articles are studies that are considered to be able to answer the research questions. This screening phase produced 31 articles that were considered to be in accordance with the needs of this research.

Table 2. The Number of Filtered Papers Table

\begin{tabular}{lrrrr}
\hline \multicolumn{1}{c}{ Journal } & Search Term & B1 & B2 \\
\hline IEEE & 17 & & 9 & 7 \\
ScienceDirect & 16 & 9 & 8 \\
SpringerLink & 105 & & 7 & 6 \\
ACM & 30 & 9 & 8 \\
ERIC & 6 & 5 & 2 \\
\hline \multicolumn{1}{c}{ Total } & 174 & 40 & 31 \\
\hline
\end{tabular}

\subsection{Subject Area}

This research also reconciles what chapters in Mathematics are used in articles obtained. It can be seen in Table 3 that the most popular chapter is the basic arithmetic chapter with 13 studies, and then the fraction chapter with 5 studies, and geometry with 4 studies. and there are 10 studies that do not mention specific chapters.

Table 3. Subject Areas Table

\begin{tabular}{|c|c|c|c|}
\hline Subject area & Research & Database & $\begin{array}{l}\text { Number of } \\
\text { Articles }\end{array}$ \\
\hline \multirow[b]{2}{*}{ Fraction } & [4], [5] & IEEE & \multirow{2}{*}{ 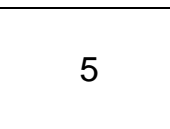 } \\
\hline & $\begin{array}{c}{[6],[7]} \\
{[8]}\end{array}$ & $\begin{array}{l}\text { ScienceDirect } \\
\text { Springer Link }\end{array}$ & \\
\hline \multirow{3}{*}{ Arithmetic } & {$[9],[10],[11],[12]$} & IEEE & \multirow{3}{*}{13} \\
\hline & [13], [14], [15], & ScienceDirect & \\
\hline & $\begin{array}{c}\text { [17], [18] } \\
{[19],[20],[21]}\end{array}$ & $\begin{array}{c}\text { ERIC } \\
\text { Springer Link }\end{array}$ & \\
\hline \multirow{5}{*}{$\begin{array}{c}\text { decimals } \\
\text { negative numbers } \\
\text { spatial thinking }\end{array}$} & [12], [22] & IEEE & \multirow[b]{2}{*}{4} \\
\hline & $\begin{array}{l}\text { [17], } \\
\text { [23] }\end{array}$ & $\begin{array}{l}\text { ERIC } \\
\text { ACM }\end{array}$ & \\
\hline & [7] & ScienceDirect & 1 \\
\hline & [7] & ScienceDirectt & 1 \\
\hline & [24] & ACM & 1 \\
\hline
\end{tabular}

\subsection{Game Outcomes}

Of the many articles that have been obtained, with various types of subject areas in the Mathematics subject, various kinds of learning objectives are also expected to be found in these studies. This includes learning outcomes at the cognitive level to the emotional level. In Table 4 Shows the various types of learning objectives using the game intended in the studies that have been obtained. Most of these studies, 12 studies focused on skill improvement, 6 studies focused on material understanding, 5 studies focused on learning motivation, and 5 studies focused on knowledge acquisition.

\subsection{Articles that answer the research questions}

After this overview is carried out, out of the 31 articles selected, the answers to the research questions that have been made have been obtained. The following is a discussion of the answers to the research questions. 


\begin{tabular}{llcc}
\hline \multicolumn{1}{c}{ Game Outcomes } & \multicolumn{1}{c}{ Research } & Database & Total \\
\hline \multirow{3}{*}{ motivation } & {$[11]$,} & IEEE & \\
& {$[17],[2]$} & ERIC & 4 \\
& {$[23],[25],[10],[5],[12],[22]$} & ACM & \\
\hline \multirow{3}{*}{ understanding } & {$[4],[9]$,} & IEEE & \\
& {$[6]$} & ScienceDirect & 12 \\
& {$[19],[26],[8],[20],[21]$} & SpringerLink & \\
\hline \multirow{3}{*}{ skill improvement } & {$[13],[27],[28],[14],[15],[16],[7]$,} & ScienceDirect & \\
& {$[18]$,} & ERIC & 11 \\
& {$[23],[29],[24]$,} & ACM & \\
\hline \multirow{2}{*}{ Enjoyment } & {$[25]$,} & ACM & \multirow{2}{*}{2} \\
& {$[20]$} & SpringerLink & 2 \\
\hline Attraction & {$[11]$} & IEEE & 1 \\
\hline \multirow{2}{*}{ knowledge acquisition } & {$[13]$} & ScienceDirect & \\
& {$[17]$} & ERIC & 3 \\
& {$[30]$} & ACM & \\
\hline
\end{tabular}

$R Q 1$. What type or type of game is used?

Of the 31 articles selected, a review has been conducted to get the answer from the first research question, which is about the type of game used in the study for learning media. In Table 5 it can be seen that the type of game that is most used is puzzle game. There are 13 studies that utilize puzzle games for Mathematics learning. The next popular type of game is the type of simulation game with 7 studies, then mini-games with 5 researches, and augmented reality games (AR) with 4 researches. From these results, it can be concluded that puzzle-games are considered the type of game that is suitable for learning Mathematics by most researchers.

Table 5. Resarches Based on Game Type Table

\begin{tabular}{|c|c|c|c|}
\hline Game Type & Research & Data-Base & $\begin{array}{c}\text { Number of } \\
\text { Articles }\end{array}$ \\
\hline \multirow{4}{*}{ Simulation } & [4], [9], [10] & IEEE & \multirow{4}{*}{7} \\
\hline & [27] & ScienceDirect & \\
\hline & [23] & $\mathrm{ACM}$ & \\
\hline & [19], [9] & Springer Link & \\
\hline \multirow{5}{*}{ Puzzle } & {$[9],[5]$} & IEEE & \multirow{5}{*}{13} \\
\hline & [6], [13], [28], [15], [14], [7] & ScienceDirect & \\
\hline & [17] & ERIC & \\
\hline & [31], [29], [24] & ACM & \\
\hline & [26] & Springer Link & \\
\hline \multirow{2}{*}{ arcade } & [16] & ScienceDirect & \multirow{2}{*}{2} \\
\hline & [26] & Springer Link & \\
\hline adventure & [23], [24] & $\mathrm{ACM}$ & 2 \\
\hline card game & [20] & Springer Link & 1 \\
\hline narative & {$[19],[26]$} & Springer Link & 2 \\
\hline \multirow{3}{*}{ mini game } & [28], [15], [14] & ScienceDirect & \multirow{3}{*}{5} \\
\hline & [32] & ACM & \\
\hline & [21] & Springer Link & \\
\hline \multirow{2}{*}{ AR game } & [11], [22] & IEEE & \multirow{2}{*}{4} \\
\hline & [30], [25] & ACM & \\
\hline gamification & [12] & IEEE & 1 \\
\hline multiplayer & [20] & Springer Link & 1 \\
\hline Quiz & [30] & ACM & 1 \\
\hline
\end{tabular}


RQ2. What are the main elements of the game applied in the game used?

According to Jabbar and Felicia (2015) [3], there are 4 main elements in the game that influence the learning process and results that utilize the game. These 4 elements are elements of motivation, fun, interactive, and multimedia. In Table 6, we can see that all research applies a reward and reciprocal game (feedback) system to the players. Besides that, the system level is also widely applied, namely in 20 studies, this proves that the level system is considered to be able to support the element of pleasure in the game.

Table 6. Main Gaming-Elements Table

\begin{tabular}{llc}
\hline \multicolumn{2}{c}{ Main gaming elements } & $\begin{array}{c}\text { Number of } \\
\text { Articles }\end{array}$ \\
\hline \multirow{2}{*}{ motivational } & reward & 31 \\
& competition & 2 \\
\hline \multirow{2}{*}{ fun } & story & 9 \\
& level & 20 \\
\hline \multirow{3}{*}{ interactive } & feedback & 31 \\
& AR & 3 \\
& Gyroscope & 1 \\
\hline
\end{tabular}

RQ3. What evaluation method is used to measure the results of the study?

To conduct research that uses games as learning media, we need to know what testing methods are appropriate for measuring the results of these studies. So after conducting a literature review, we can see in Table 7 what methods are used in research that uses games for learning mathematics. The most popular method for testing is the quasi-experimental method, there are 22 studies that apply it. In addition, 8 studies used questionnaires, and 2 studies used game log data.

Table 7. Researches Based On Evaluation Methods Table

\begin{tabular}{clcc}
\hline $\begin{array}{c}\text { Evaluation } \\
\text { Method }\end{array}$ & \multicolumn{1}{c}{ Research } & Data-Base & $\begin{array}{c}\text { Number of } \\
\text { Articles }\end{array}$ \\
\hline \multirow{4}{*}{ Quasi- } & {$[4],[9],[10],[5]$} & IEEE & \\
Experiment & {$[6],[13],[27],[28],[15],[14],[16]$,} & Science & \\
& {$[18]$} & Direct & 22 \\
& {$[23],[33],[29]$} & ERIC & \\
& {$[19],[26],[31],[34],[20],[21],[8]$} & ACM & \\
& {$[10]-[12]$} & Springer Link \\
Questionaire & {$[28]$} & IEEE \\
& {$[17]$} & Science & \\
& {$[25],[31]$} & Direct & 8 \\
& {$[21]$} & ERIC & \\
\hline Log & {$[23],[32]$} & ACM & \\
\hline
\end{tabular}

\section{Discussion}

\subsection{Subject Area and Game Type}

After a review of selected studies, it can be seen that there are several chapters in the popular Mathematics course. These chapters include basic arithmetic, fractions, geometry, and several other chapters. Basic arithmetic is the most popular chapter in the last 5 years, then chapters, and geometry. This can be used by researchers and developers to be able to learn about what types of games are suitable for these popular chapters. Besides that, we can see many research opportunities in chapters that are still few researchers doing research in them.

In Figure 2, it can be seen that for basic arithmetic learning, the type of game that is widely used is puzzle-games and simulation games. The fractional chapter also uses the same 2 types of games, puzzle-games and simulation games. And in the geometry chapter, there are 4 different types in 4 different studies 4 , namely puzzle-games, gamification, augmented reality games, and 
simulation games. In addition, there are 3 other chapters that share the type of puzzle-game, namely the chapter of decimal numbers, negative numbers, and the sharpening of spatial thinking skills. So it can be concluded that the type of puzzle-game can be applied to learning media in basic arithmetic, fractions, geometry, decimal numbers, negative numbers, and also to practice spatial thinking skills.
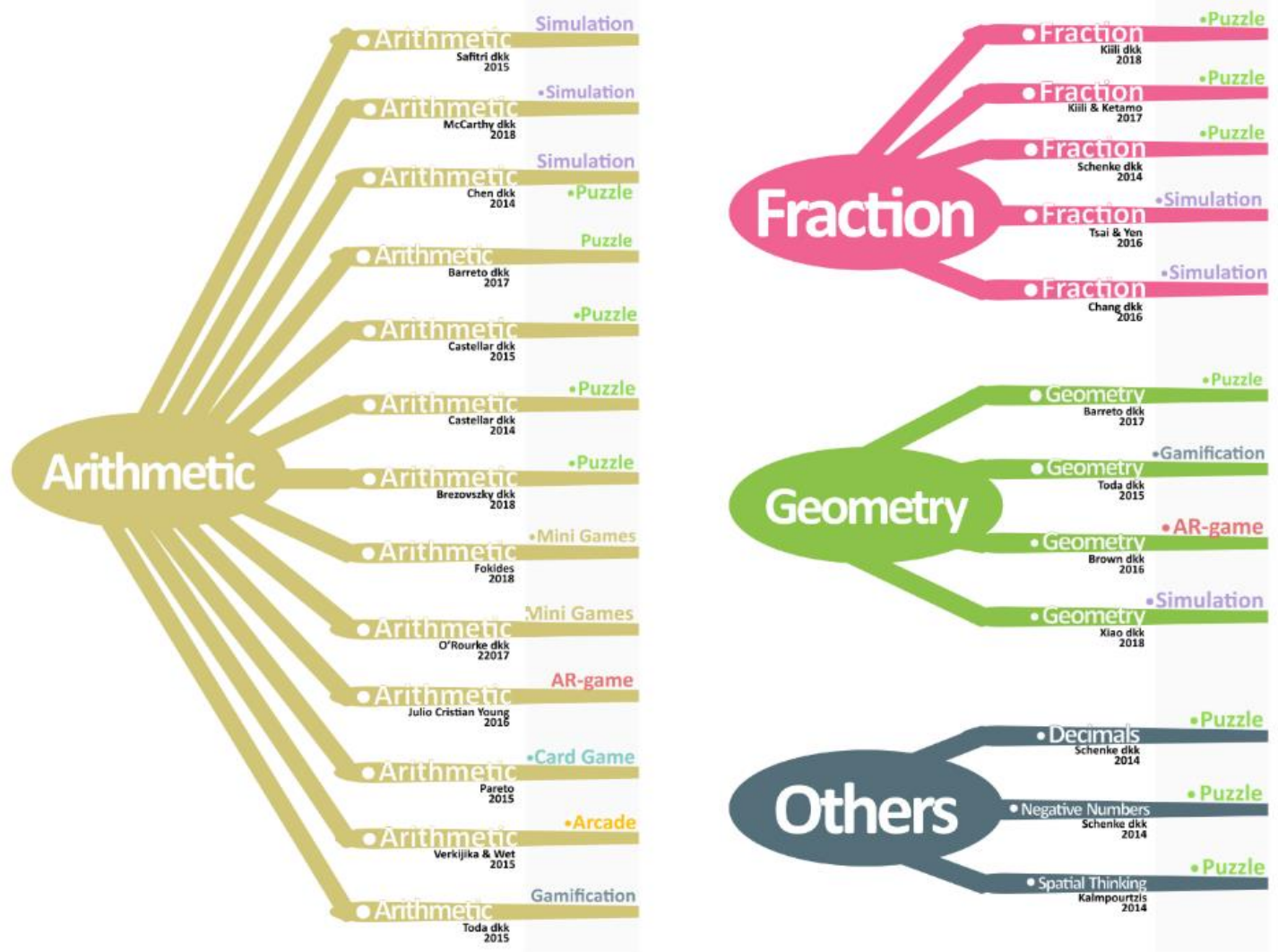

Figure 2. Subject Area and Game Type Diagram

\subsection{Game Types and Elements of Game Outcomes}

To reach the desired learning outcomes, we need to know the supporting factors. Among these factors are the type of game and the main elements of the game. After a review of selected studies, this study will discuss the correlation between the type of game, the main elements of the game being applied, and the learning outcomes using the game.

Figure 3 describes the main elements of the game being applied and the learning outcomes in the puzzle type game that is used. We can see that all of the research applied a system of levels, rewards, and feedback on the games used. These elements are used as a support to achieve the desired learning outcomes, namely improvement in skills, understanding of the material, acquisition of knowledge related to material, and motivation to learn.

In Figure 4, it is explained about the main elements of the game being applied and the learning outcomes in studies that use simulation games as a medium for learning Mathematics. We can see that the elements applied to all games used are the reward and feedback systems. In the simulation game, there are differences in fun elements that are applied with those applied to puzzle-type games. We can see that almost all apply the story elements in the game that are used. If we observe, the game that applies the story element aims to provide understanding regarding the material being studied. But in addition, simulation games can also be used as learning media that aim to provide learning motivation, skill improvement, and material acquisition.

The other game types in term of main elements of the game that are applied and the learning results are obtained in mini-games, AR-games, gamification, card-games, and arcade games. Research that utilizes mini-games has learning outcomes in the form of understanding material and improving skills by implementing a system of rewards and feedback. Research that 
uses AR-games emphasizes material understanding and learning motivation. The gamification approach is used by researchers to understand and memorize subject matter.

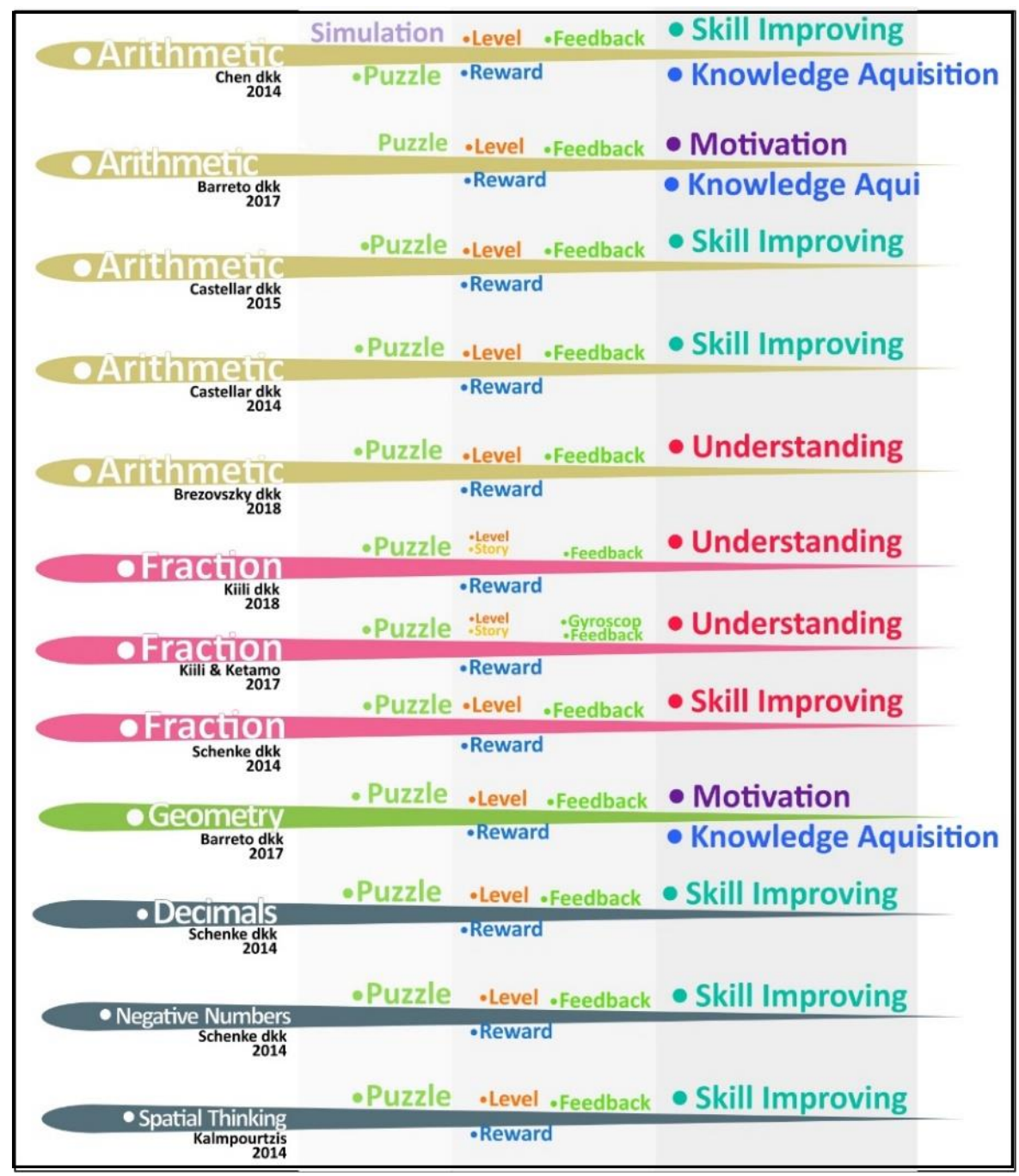

Figure 3. Puzzle-Game Elements and Outcomes Diagram

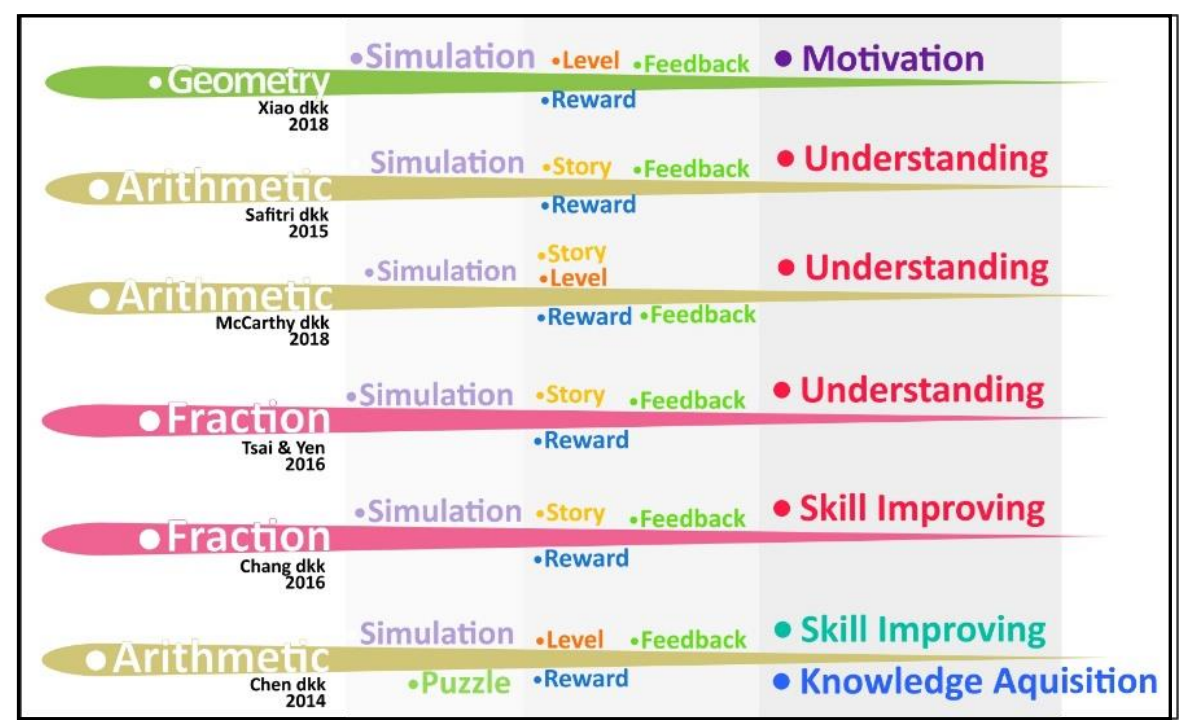

Figure 4. Simulation-Game Elements and Outcomes Diagram 


\section{Conclusion}

Overall, this research has summarized the studies that have obtained positive results from using games as learning media, especially in Mathematics. In the past 5 years, this topic has become a popular thing in the world of scientific research. There are 3 popular chapters that are carried out research in it to improve learning by playing games. Basic arithmetic is the most popular chapter of the total number of 13 studies in the last 5 years, then the chapter of fractions with the number of 5 studies, and geometry with 4 studies, the rest there are other chapters such as decimal numbers, negative numbers, and others.

The popular type of game for Mathematics learning is puzzle-game with 12 researches and simulation games with 6 researches. Puzzle-games are applied to various chapters in Mathematics courses, such as basic arithmetic with a total of 6 studies, fractions with a number of 3 studies, geometry, decimal numbers, negative numbers, and spatially spatial thinking abilities. While the simulation game was applied to the basic arithmetic chapter with 3 studies, fractions with the number of studies, and the geometry of 1 study.

There is one topic that is gaining in popularity is the use of new technology, namely Augmented Reality (AR). The technology began to be utilized in games for learning Mathematics in several different chapters, such as geometry, basic arithmetic, and others. Augmented Reality is proven to help learning in motivating and improving students' spatial abilities.

\section{References}

[1] E. A. Boyle et al., "An update to the systematic literature review of empirical evidence of the impacts and outcomes of computer games and serious games," Comput. Educ., Vol. 94, Pp. 178-192, 2016.

[2] T. M. Connolly, E. A. Boyle, E. MacArthur, T. Hainey, and J. M. Boyle, "A systematic literature review of empirical evidence on computer games and serious games," Comput. Educ., Vol. 59, No. 2, Pp. 661-686, 2012.

[3] A. I. Abdul Jabbar and P. Felicia, "Gameplay Engagement and Learning in Game-Based Learning: A Systematic Review," Rev. Educ. Res., Vol. 85, No. 4, Pp. 740-779, 2015.

[4] T. Chih-Hsiao and J. C. Yen, "Effect of an Equivalent Fractions Digital Game on the Learning Outcome, Motivation, and Flow Types among Elementary School Students," Proc. - 5th Int. Conf. Educ. Innov. through Technol. EITT 2016, Pp. 70-75, 2017.

[5] K. Kiili and H. Ketamo, "Evaluating Cognitive and Affective Outcomes of a Digital GameBased Math Test," IEEE Trans. Learn. Technol., Vol. 11, No. 2, Pp. 255-263, 2018.

[6] K. Kiili, K. Moeller, and M. Ninaus, "Evaluating the effectiveness of a game-based rational number training - In-game metrics as learning indicators," Comput. Educ., Vol. 120, No. February, Pp. 13-28, 2018.

[7] K. Schenke, T. Rutherford, and G. Farkas, "Alignment of game design features and state mathematics standards: Do results reflect intentions?," Comput. Educ., Vol. 76, Pp. 215224, 2014.

[8] M. Chang, M. A. Evans, S. Kim, A. Norton, K. Deater-Deckard, and Y. Samur, "The effects of an educational video game on mathematical engagement," Educ. Inf. Technol., Vol. 21, No. 5, Pp. 1283-1297, 2016.

[9] H. R. Chen, C. H. Jian, W. S. Lin, P. C. Yang, and H. Y. Chang, "Design of digital gamebased learning in elementary school mathematics," Proc. - 2014 7th Int. Conf. Ubi-Media Comput. Work. U-MEDIA 2014, Pp. 322-325, 2014.

[10] A. G. Safitri, A. S. Prihatmanto, and P. H. Rusmin, "Design and implementation of educational game based on thematic curriculum using three layered thinking model (Case study: Applying number and social arithmetic in the real life)," Proc. 2015 4th Int. Conf. Interact. Digit. Media, ICIDM 2015, no. Icidm, 2016.

[11] J. C. Young, M. B. Kristanda, and S. Hansun, "ARmatika: 3D game for arithmetic learning with Augmented Reality technology," 2016 Int. Conf. Informatics Comput. ICIC 2016, No. Icic, Pp. 355-360, 2017.

[12] A. M. Toda, R. S. Do Carmo, V. Campos, A. L. Da Silva, and J. D. Brancher, "Evaluation of SiGMa, an empiric study with Math teachers," Proc. - Front. Educ. Conf. FIE, Vol. 2014, 2015. 
[13] B. Brezovszky et al., "Effects of a mathematics game-based learning environment on primary school students' adaptive number knowledge," Comput. Educ., Vol. 128, No. September 2018, Pp. 63-74, 2019.

[14] L. de M. Elena Núñez Castellar, Jan Van Looy, Arnaud Szmalec, "Improving arithmetic skills through gameplay: Assessment of the effectiveness of an educational game in terms of cognitive and affective learning outcomes," J. Med. Assoc. Thail., Vol. 99, No. 2, Pp. 175$181,2016$.

[15] E. Núñez Castellar, A. All, L. De Marez, and J. Van Looy, "Cognitive abilities, digital games and arithmetic performance enhancement: A study comparing the effects of a math game and paper exercises," Comput. Educ., Vol. 85, Pp. 123-133, 2015.

[16] S. F. Verkijika and L. De Wet, "Using a brain-computer interface $(\mathrm{BCl})$ in reducing math anxiety: Evidence from South Africa," Comput. Educ., Vol. 81, Pp. 113-122, 2015.

[17] D. Barreto, L. Vasconcelos, and M. Orey, "Motivation and learning engagement through playing math video games," Malaysian J. Learn. Instr., Vol. 14, No. 2, Pp. 1-21, 2017.

[18] J. O'Rourke, S. Main, and S. Hill, "Technology in the Classroom: Improving Automaticity in Mental-maths in Primary-aged Students," Aust. J. Teach. Educ., Vol. 42, No. 10, Pp. 50-70, 2017.

[19] E. McCarthy, M. Tiu, and L. Li, "Learning Math with Curious George and the Odd Squad: Transmedia in the Classroom," Technol. Knowl. Learn., Vol. 23, No. 2, Pp. 223-246, 2018.

[20] L. Pareto, "A teachable agent game engaging primary school children to learn arithmetic concepts and reasoning," Int. J. Artif. Intell. Educ., Vol. 24, No. 3, Pp. 251-283, 2014.

[21] E. Fokides, "Digital educational games and mathematics. Results of a case study in primary school settings," Educ. Inf. Technol., Vol. 23, No. 2, Pp. 851-867, 2018.

[22] J. E. G. TeAirra M. Brown, Tiffanie R. Smith, Joseph L. Gabbard, "Augmenting Mathematical Education for Minority Students," Vol. 94, No. 17, Pp. 6229-6230, 2016.

[23] Z. Xiao, Y. Yao, and W.-T. Fu, "Cubicle: An Adaptive Educational Gaming Platform for Training Spatial Visualization Skills," Proc. 23rd Int. Conf. Intell. User Interfaces Companion - IUI'18, Pp. 1-2, 2018.

[24] G. Kalmpourtzis, "Find the Jackalop: A Game Enhancing Young Children's Spatial Thinking," CHI '14 Ext. Abstr. Hum. Factors Comput. Syst., Pp. 1165-1170, 2014.

[25] F. A. Pritami and I. Muhimmah, "Digital Game Based Learning using Augmented Reality for Mathematics Learning," Proc. 2018 7th Int. Conf. Softw. Comput. Appl. - ICSCA 2018, Pp. 254-258, 2018.

[26] K. Trujillo, B. Chamberlin, K. Wiburg, and A. Armstrong, "Measurement in Learning Games Evolution: Review of Methodologies Used in Determining Effectiveness of Math Snacks Games and Animations," Technol. Knowl. Learn., Vol. 21, No. 2, Pp. 155-174, 2016.

[27] S. Vandercruysse et al., "The effectiveness of a math game: The impact of integrating conceptual clarification as support," Comput. Human Behav., Vol. 64, Pp. 21-33, 2016.

[28] M. Maertens, M. Vandewaetere, F. Cornillie, and P. Desmet, "From pen-and-paper content to educational math game content for children: A transfer with added difficulty," Int. J. ChildComputer Interact., Vol. 2, No. 2, Pp. 85-92, 2014.

[29] Z. Peddycord-Liu, C. Cody, S. Kessler, T. Barnes, C. F. Lynch, and T. Rutherford, "Using Serious Game Analytics to Inform Digital Curricular Sequencing," Proc. Annu. Symp. Comput. Interact. Play - CHI Play '17, Pp. 195-204, 2017.

[30] J. Li, J. Hu, E. Van der Spek, and L. Feijs, "SEE ME ROAR: Self-determination Enhanced Engagement for Math Education Relying On Augmented Reality," Vol. 45, No. 5, Pp. 10281036, 2017.

[31] I. Arroyo, M. Micciollo, J. Casano, E. Ottmar, T. Hulse, and M. M. Rodrigo, "Wearable Learning: Multiplayer Embodied Games for Math," Proc. Annu. Symp. Comput. Interact. Play, Pp. 205-216, 2017.

[32] M. H. Falakmasir, J. P. Gonzalez-Brenes, G. J. Gordon, and K. E. DiCerbo, "A Data-Driven Approach for Inferring Student Proficiency from Game Activity Logs," Proc. Third ACM Conf. Learn.@Scale - L@S '16, Pp. 341-349, 2016.

[33] T. Bouzid, H. Darhmaoui, and F. Kaddari, "Promoting elementary mathematics learning through digital games," Proc. 2nd Int. Conf. Big Data, Cloud Appl. - BDCA'17, Pp. 1-4, 2017.

[34] I. Arroyo, B. P. Woolf, W. Burelson, K. Muldner, D. Rai, and M. Tai, "A multimedia adaptive tutoring system for mathematics that addresses cognition, metacognition and affect," Int. J. Artif. Intell. Educ., Vol. 24, No. 4, Pp. 387-426, 2014.

KINETIK Vol. 4, No. 2, May 2019: 169-178 